\title{
Optimasi Kualitas Jaringan WLAN Berdasarkan Coverage Area dan Jumlah Pengguna di Fakultas Teknologi Industri UNISSULA
}

\author{
Destra Kurniatama Jatmiko ${ }^{1)}$, Budi Pramono Jati ${ }^{2)}$, dan Jenny Putri Hapsari ${ }^{3)}$ \\ ${ }^{1,2,3)}$ Fakultas Teknologi Industri dan Universitas Islam Sultan Agung Semarang \\ 1,2,3) Jl. Raya Kaligawe Km 4 Semarang 50112 \\ e-mail: destra@ std.unissula.ac.id ${ }^{1)}$, budipramono@unissula.ac.id ${ }^{2)}$,jenny@unissula.ac.id ${ }^{3)}$
}

\begin{abstract}
WLAN is a wireless telecommunications network in the process of distributing data or information. This network is easier and economical to build because without having to do the design of cable lines and no need for cables as devices. In the main building of the Faculty of Industrial Technology UNISSULA already has a WLAN network, but there are blankspots in several areas. The layout and number of Access Points (AP) greatly affect the quality of the WLAN signal, besides the number of users. Optimization is done by comparing the number of AP exiting with the number of APs based on the coverage area and number of users. The parameters used for network quality are signal strength more than -75 dBm and Signal to Noise Ratio (SNR) of more than $25 \mathrm{~dB}$. Retrieval of existing network quality data with walktest method using the Ekahau Site Survey software. The quality of signal strength and SNR based on the coverage area is calculated using the COST 231 Multiwall method, while those based on the number of users are calculated using the ratio of Airtime per Device (APD) to Number of Device (NoD). The next step, simulating the AP layout using the Ekahau Site Survey software. The research concluded that each floor only requires 2 pieces AP. The percentage value of signal strength> $-75 \mathrm{dBm}$ after optimization is $86 \%$, 89.8\%, and 87.4\% for floors 1, 2, and 3 respectively. While the SNR percentage values $>25 \mathrm{~dB}$ after optimization are $81.1 \%, 86.3 \%$, and $84.5 \%$ for floors 1, 2, and 3 respectively.
\end{abstract}

Keywords: WLAN, Access Point, Signal Strength, SNR.

\section{ABSTRAK}

WLAN adalah jaringan telekomunikasi tanpa kabel dalam proses pendistribusian data atau informasi. Jaringan ini lebih mudah dan ekonomis untuk dibangun karena tanpa harus melakukan perancangan jalur-jalur kabel dan tidak perlu kabel sebagai perangkat. Pada gedung utama Fakultas Teknologi Industri UNISSULA sudah ada jaringan WLAN, tapi terdapat blank spot pada beberapa area. Peletakan dan jumlah Access Point (AP) sangat mempengaruhi kualitas sinyal WLAN, selain itu jumlah pengguna. Optimasi dilakukan dengan membandingkan jumlah AP exiting dengan jumlah AP berdasarkan coverage area dan jumlah pengguna. Parameter yang digunakan untuk kualitas jaringan adalah signal strength lebih dari $-75 \mathrm{dBm}$ dan Signal to Noise Ratio (SNR) lebih dari $25 \mathrm{~dB}$. Pengambilan data kualitas jaringan existing menggunakan metode walktest menggunakan software Ekahau Site Survey. Kualitas signal strength dan SNR berdasarkan coverage area dihitung menggunakan metode COST 231 Multiwall, sedangkan yang berdasarkan jumlah pengguna dihitung menggunakan rasio Airtime per Device (APD) dengan Number of Device (NoD). Langkah berikutnya, simulasi peletakan AP menggunakan software Ekahau Site Survey. Penelitian menghasilkan kesimpulan bahwa setiap lantai hanya membutuhkan minimal AP sebanyak 2 buah. Nilai persentase signal strength yang > -75 dBm setelah dilakukan optimasi adalah $86 \%, 89,8 \%$, dan 87,4\% untuk lantai 1, 2, dan 3 secara berurutan. Sedangkan nilai persentase SNR yang > $25 \mathrm{~dB}$ setelah dilakukan optimasi adalah $81,1 \%, 86,3 \%$, dan $84,5 \%$ untuk lantai 1, 2, dan 3 secara berurutan.

Kata kunci: WLAN, Access Point, Signal Strength, SNR.

\section{Pendahuluan}

$\mathrm{W}$ LAN (Wireless Local Area Network) adalah jaringan telekomunikasi tanpa kabel dalam proses pendistribusian data atau informasi. Jaringan ini lebih mudah dan ekonomis untuk dibangun karena tanpa harus melakukan perancangan jalur-jalur kabel dan tidak perlu kabel sebagai perangkat. WLAN saat ini menggunakan dua frekuensi yaitu $2,4 \mathrm{GHz}$ dan 5 GHz. Pada frekuensi $2,4 \mathrm{GHz}$, sering terjadi interferensi dikarenakan frekuensi ini juga digunakan oleh Bluetooth. Sedangkan untuk frekuensi $5 \mathrm{GHz}$ jarang terjadi interferensi tetapi memiliki daya pancar lebih rendah.[1]

Optimasi propagasi WLAN frekuensi 2,4 GHz yang terpasang di outdoor maupun indoor diperlukan karena banyaknya interferensi yang terjadi. Karakteristik propagasi indoor dikategorikan menjadi tiga model, yaitu model teoritis (statistik), model empiris, dan model fisik (site-spesific)[2][3]. Model teoritis dilakukan dengan mengukur aspek propagasi yang meliputi Received Signal Strength Indicator (RSSI), kecepatan data, Signal to Noise Ratio (SNR), dan channel Access Point (AP). Model empiris dilakukan dengan pemantauan secara langsung untuk memperoleh data yang ada di lapangan. [4]Selain itu, optimasi dapat dilakukan dengan membandingkan jumlah kapasitas pengguna dengan jumlah AP yang digunakan.

Gedung utama Fakultas Teknologi Universitas Islam Sultan Agung memilki luas $4000 \mathrm{~m}^{2}$ dengan 3 lantai. Jumlah pengguna aktif sekitar 286 orang. Gedung ini 
dilengkapi dengan area hotspot dengan AP yang tersebar pada ketiga lantai. Pada beberapa area, pengguna sering tidak dapat mengakses internet dengan baik. Hal ini dikarenakan ada beberapa AP yang tidak dapat diakses secara umum dan interferensi antar AP pada lantai yang sama.

Berdasarkan latar belakang permasalahan tersebut, maka penelitian ini akan membahas optimasi jangkauan WLAN berdasarkan coverage area dan banyaknya pengguna. Analisa penelitian ini berdasarkan pada data yang didapat dari walktest dengan menggunakan software Ekahau Site Survey.[5]

Perumusan masalah pada penelitian ini adalah berapa kualitas WLAN pada gedung utama Fakultas Teknologi Industri Universitas Islam Sultan Agung, bagaimana merancang peletakan AP berdasarkan coverage area dan jumlah pengguna agar mendapatkan kualitas jaringan WLAN yang optimal.

Tujuan dari penelitian ini adalah menganalisa kualitas WLAN pada gedung utama Fakultas Teknologi Industri Universitas Islam Sultan Agung, merancang peletakan AP agar mendapatkan kualitas jaringan yang optimal, dan meningkatkan kualitas dan jangkauan jaringan.

\section{TinjauAn Pustaka}

Penelitian sebelumnya yang dilakukan oleh Zawiyah Saharuna, membahas mengenai desain jaringan WLAN pada kampus 2 Politeknik Negeri Ujung Pandang. Penelitian ini menyimpulkan bahwa untuk mendesain suatu jaringan WLAN harus memperhatikan cakupan area dan kapasitas, karena jika hanya memperhatikan cakupan area maka hanya memenuhi $77 \%$ kebutuhan AP. [6]

Penelitian yang telah dilakukan oleh Bekti Widyaningsih, membahas tentang optimasi cakupan area WLAN di gedung PPTIK Universitas Brawijaya menggunakan model propagasi empiris dan teoritis. Pada penelitian ini menyimpulkan bahwa jaringan WLAN dengan rata-rata RSSI $-40 \mathrm{dBm}$ sampai -55 $\mathrm{dBm}$, dengan power 17-18 dBm, dan menerapkan kanal non-overlapping untuk AP yang berdekatan. [4]

Penelitian tentang perancangan dan simulasi peletakan AP berdasarkan coverage dari jaringan dengan variasi nilai rata-rata sinyal dan daya rata-rata yang diterima pengguna lebih besar $-80 \mathrm{dBm}$, dilakukan oleh Gama Victonida. Penelitian ini menyimpulkan perlu adanya penambahan AP dan mengubah letak AP untuk mendapatkan hasil yang optimal.[7]

Pada tahun 2016 telah dilakukan penelitian tentang perencanaan WIFI di gedung Nanas Universitas Telkom. Penelitian ini menggunakan simulator RPSv5.4 dengan parameter frekuensi $2,4 \mathrm{GHz}$ dan model propagasi COST 231 Multiwall. Hasil penelitian ini menunjukkan bahwa adanya penambahan AP dan pergeseran AP untuk masing-masing lantai. Selain itu didapatkan nilai daya nilai optik $-5,12 \mathrm{dBm}$ yang menunjukkan bahwa lintasan optik dalam kondisi baik. [8]

Penelitian tentang perancangan high density wireless LAN 802.11n 2,4 GHz di ruang kelas Fakultas Ilmu Terapan Universitas Telkom yang dilakukan pada tahun 2015. Perancangan tersebut menggunakan beberapa tahapan yaitu identifikasi kemampuan perangkat pengguna, identifikasi kebutuhan throughput aplikasi pengguna, penentuan jumlah AP, pemilihan pita frekuensi, lebar kanal, kanal frekuensi. Hasil dari penelitian ini adalah dibutuhkan 3 buah AP untuk melayani 50 user dengan kebutuhan throughput aplikasi 5 Mbps.[9]

Penelitian tentang co-channel yang dilakukan di Gedung lantai 1 Fakultas Teknologi Industri telah dilakukan. Penelitian ini menggunakan prinsip teknologi cognitive radio untuk mendeteksi adanya cochannel dan level daya yang di terima. Hasil penelitian ini adalah rata-rata co-channel $63,8 \%$ dan adjacentchannel 36,1\%.[10]

Penelitian yang dilakukan di gedung utama Fakultas Teknologi Industri, Universitas Islam Sultan Agung dengan menggunakan software Ekahau Site Survey untuk mendapatkan data kualitas WLAN saat ini.

\section{Metode Penelitian}

Penelitian ini diawali dengan menentukan lokasi penelitian yang digunakan untuk pengumpulan datadata penelitian. Penelitian ini menggunakan lokasi gedung utama Fakultas Teknologi Industri Universitas Islam Sultan Agung dikarenakan adanya area dalam gedung yang susah digunakan untuk akses internet. Data-data yang dikumpulkan antara lain, denah gedung, jumlah pengguna rata-rata, perangkat AP, dan kebutuhan throughput. Setelah data di dapatkan, maka akan dilakukan walktest untuk mengetahui kualitas sinyal dalam gedung untuk setiap lantainya. Walktest ini menggunakan software Ekahau Site Survey. Dalam penelitian ini, perancangan dilakukan berdasarkan coverage area dan jumlah pengguna agar didapatkan kualitas sinyal yang optimal. Flowchart penelitian masing-masing metode dapat dilihat di Gambar 1 dan Gambar 2.

Pada perancangan berdasarkan coverage area, setelah dilakukan walktest dan didapatkan data RSSI dan SNR kemudian dilakukan analisa untuk mengetahui indeks performa dan melihat apakah sudah sesuai dengan standar yang dianjurkan. Langkah selanjutnya adalah menghitung Pathloss dan jari-jari AP. Setelah didapatkan Pathloss dan jari-jari AP kemudian dilakukan perancangan untuk mengetahui berapa radius sebuah AP dan letak AP tersebut. Perancangan ini juga harus memperhatikan faktor luas dan jenis material bangunan karena dilakukan di indoor. 


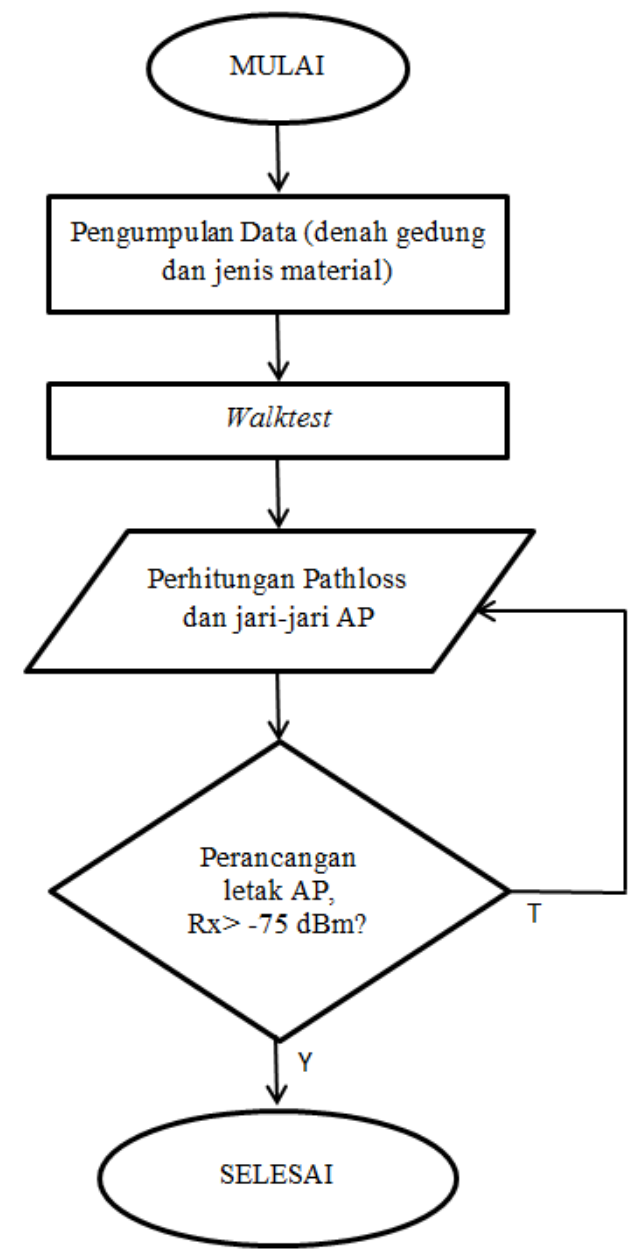

Gambar 1. Flowchart perancangan WLAN berdasarkan coverage area

Pada perancangan berdasarkan jumlah pengguna, setelah dilakukan walktest dan didapatkan data RSSI dan SNR kemudian dilakukan analisa untuk mengetahui indeks performa dan melihat apakah sudah sesuai dengan standar yang dianjurkan. Langkah selanjutnya adalah menghitung jumlah AP yang dibutuhkan. Setelah didapatkan jumlah AP kemudian dilakukan perancangan untuk mengetahui berapa radius sebuah AP dan letak AP tersebut. Perancangan ini juga harus memperhatikan faktor luas dan jenis material bangunan karena dilakukan di indoor. Peletakan AP yang kurang tepat dapat menyebabkan blankspot pada suatu titik sehingga tidak optimal.

\section{HASIl DAN PEMBahasan}

\section{A. Walktest}

Metode walktest dilakukan untuk mengetahui kualitas awal signal strength dan signal to noise ratio (SNR) dari AP yang sudah terpasang (6 buah di lantai 1, 5 buah di lantai 2, dan 2 buah di lantai 3). Walktest dilakukan dengan bantuan laptop sebagai receiver dan software Ekahau Site Survey yang digunakan untuk menampilkan daya yang telah ditangkap oleh receiver. Gambar 3 menunjukkan contoh hasil walktest untuk pengukuran signal strength di lantai 1. Sedangkan Gambar 4 menunjukkan contoh hasil walktest untuk pengukuran SNR di lantai 2.
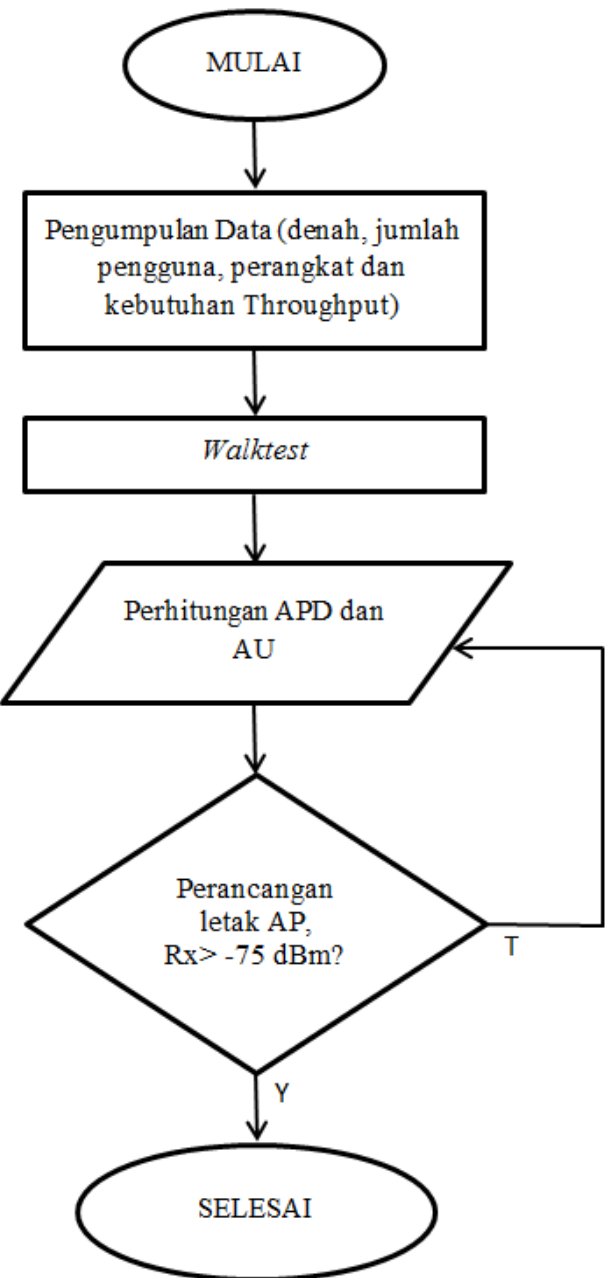

Gambar 2. Flowchart perancangan WLAN berdasarkan jumlah pengguna

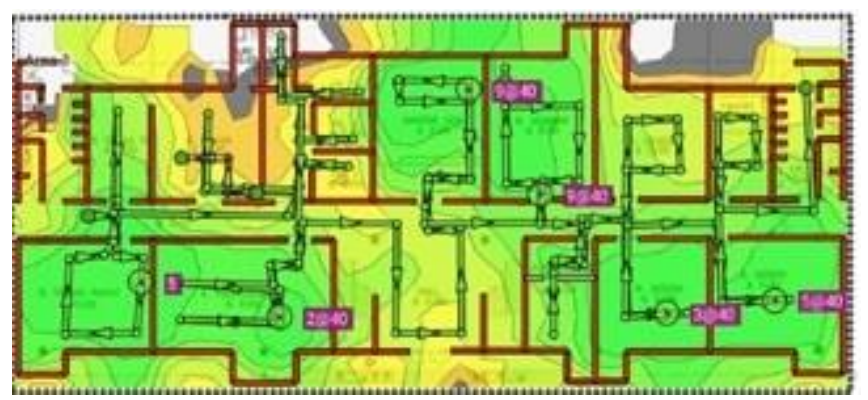

Gambar 3. Visualisasi signal strength lantai 1

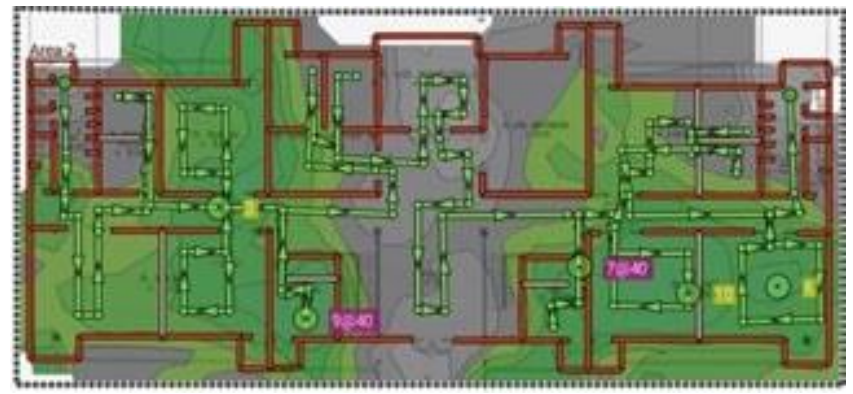

Gambar 4. Visualisasi SNR lantai 2

Hasil visualisasi signal strength dan SNR hasil walktest di ketiga lantai ditunjukkan pada Tabel I. 
TABEL I NILAI SIGNAL STRENGTH DAN SNR HASIL WALKTEST

\begin{tabular}{ccc|cc}
\hline \multirow{2}{*}{ Lantai } & \multicolumn{2}{c|}{ Signal Strength } & \multicolumn{2}{c}{ SNR } \\
\cline { 2 - 5 } & $>-75 \mathrm{dBm}$ & $<-75 \mathrm{dBm}$ & $>25 \mathrm{~dB}$ & $<25 \mathrm{~dB}$ \\
\hline 1 & $93,7 \%$ & $5,3 \%$ & $74,3 \%$ & $24,7 \%$ \\
2 & $86,2 \%$ & $12,8 \%$ & $59,8 \%$ & $39,2 \%$ \\
3 & $93,6 \%$ & $5,4 \%$ & $91,4 \%$ & $7,6 \%$ \\
\hline \hline
\end{tabular}

\section{B. Perancangan WLAN berdasarkan Coverage}

Area

Perhitungan nilai MAPL harus dilakukan sebelum penentuan jumlah AP. Pada teori, nilai dari power transmit $\left(\mathrm{P}_{\mathrm{TX}}\right)$ adalah $20 \mathrm{dBm}$ atau $100 \mathrm{~mW}$, gain antenna $\left(\mathrm{G}_{\text {antena }}\right)$ pada $A P$ adalah $5 \mathrm{dBi}$. Nilai dari fading margin untuk tipical WLAN adalah sebesar $10 \mathrm{~dB}$, Loss Saluran ( $\left.\mathrm{L}_{\text {saluran }}\right)$ bernilai $0 \mathrm{~dB}$ karena nirkabel, sensitifitas receiver $\left(S_{\mathrm{RX}}\right)$ bernilai $-75 \mathrm{dBm}$. Sehingga nilai MAPL adalah:

$$
\begin{aligned}
& M A P L=P_{T X}-L_{\text {Saluran }}+G_{\text {Antena }}-F_{m \arg \text { in }}-S_{R X} \\
& M A P L=20-0+5-10-(-75) \\
& M A P L=90 \mathrm{dBm}
\end{aligned}
$$

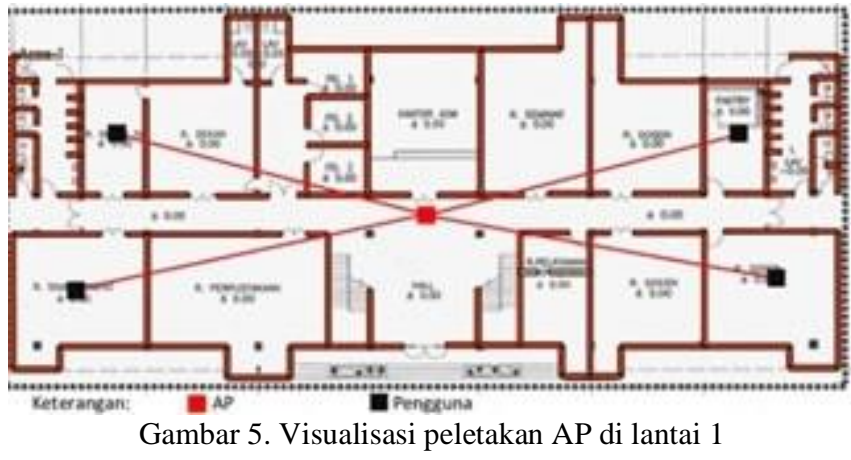

Pada lantai 1, apabila AP diletakkan pada pusat denah lantai 1 dengan beberapa pengguna berada di titik (Gambar 5), maka akan didapatkan bahwa rata-rata AP melewati 3 buah dinding berjenis brick yang memiliki nilai pelemahan sebesar $8 \mathrm{~dB}$ dan melewati 1 buah dinding berjenis dry wall dengan nilai pelemahan sebesar $3 \mathrm{~dB}$ serta nilai Free Space Loss $\left(\mathrm{L}_{\mathrm{o}}\right)$ sebesar 40,2 dB. Sehingga estimasi coverage area layanan dari 1 buah AP dapat dihitung sebagai berikut:

$$
\begin{aligned}
& L_{P}=L_{o}+20 \log d+\sum_{i=1}^{k w} k_{w i} L_{w i} \\
& 90=40,2+20 \log d+(3 \times 8)+(1 \times 3) \\
& 22,8=20 \log d \\
& d=13,804 m
\end{aligned}
$$

Luas area untuk setiap lantai adalah 1313,64 $\mathrm{m}^{2}$. Sedangkan coverage area WLAN dengan acuan satu buah link adalah

$$
\begin{aligned}
& \text { Luas }_{\text {Coverage Area }}=2,6 \times d^{2} \\
& \text { Luas }_{\text {Coverage Area }}=2,6 \times(13,804)^{2} \\
& \text { Luas }_{\text {Coverage Area }}=495,419 \mathrm{~m}^{2}
\end{aligned}
$$

$$
\begin{aligned}
& N_{A P}=\frac{\text { Luas Area yang direncanakan }}{\text { Luas }_{\text {CoverageArea }}} \\
& N_{A P}=\frac{1313,64}{495,419}=2,46=2
\end{aligned}
$$

Dengan cara peletakan dan perhitungan yang sama, didapatkan jumlah AP untuk lantai 2 dan 3 sebagai berikut:

$$
\text { TABEL II JUMLAH AP BERDASARKAN COVERAGE AREA }
$$

\begin{tabular}{cc}
\hline Lantai & Jumlah AP \\
\hline 1 & 2 \\
2 & 2 \\
3 & 1 \\
\hline
\end{tabular}

Hasil perancangan berdasarkan coverage area, kemudian dilakukan pengukuran signal strength dan SNR di setiap lantai, dan hasil presentase untuk setiap lantai ditunjukkan pada Tabel III.

TABEL III NILAI SIGNAL STRENGTH DAN SNR BERDASARKAN COVERAGE AREA

\begin{tabular}{ccc|cc}
\hline \multirow{2}{*}{ Lantai } & \multicolumn{2}{c|}{ Signal Strength } & \multicolumn{2}{c}{ SNR } \\
\cline { 2 - 5 } & $>-75 \mathrm{dBm}$ & $<-75 \mathrm{dBm}$ & $>25 \mathrm{~dB}$ & $<25 \mathrm{~dB}$ \\
\hline 1 & $86 \%$ & $13 \%$ & $81,1 \%$ & $17,1 \%$ \\
2 & $89,8 \%$ & $9,2 \%$ & $86,3 \%$ & $12,7 \%$ \\
3 & $81,9 \%$ & $17,1 \%$ & $78,1 \%$ & $20,9 \%$ \\
\hline \hline
\end{tabular}

\section{Perancangan WLAN berdasarkan Jumlah Pengguna}

Penentuan jumlah AP yang dibutuhkan pada gedung utama Fakultas Teknologi Industri Universitas Islam Sultan Agung berdasarkan jumlah pengguna, diawali dengan pencarian data rata-rata pengguna layanan pada gedung. Data pengguna dalam gedung utama rata-rata 286 orang, dan estimasi sebanyak $75 \%$ menggunakan layanan dalam waktu yang bersamaan di waktu jam sibuk. Penelitian ini menggunakan protokol $802.11 \mathrm{n}$ jadi data rate bernilai 450 Mbps dan nilai association rate adalah $144 \mathrm{Mbps}$, sehingga bandwidth untuk setiap pengguna dapat dihitung, yaitu:

$$
\begin{aligned}
& \text { Bandwidth }=\frac{\left(\frac{\text { DataRate AP }}{2}\right)}{\text { MaxUser }} \\
& \text { Bandwidth }=\frac{\left(\frac{450}{2}\right)}{286}=786,713 \mathrm{Kbps}=0,786 \mathrm{Mbps}
\end{aligned}
$$

Perhitungan menunjukkan bahwa bandwidth satu pengguna di setiap lantai sebesar 0,786 Mbps. Jadi dapat dihitung kebutuhan bandwidth dari tiga lantai adalah:

BandwidthGedung $=0,786 \times 286 \times 3=674,388 \mathrm{Mbps}$

Sehingga jumlah AP pada setiap lantai adalah: 
Jumlah AP dapat dihitung sebagai berikut:

$$
\begin{aligned}
N_{A P} & =\frac{B w_{\text {user }} \times N_{\text {user }} \times \% \text { Activity Rate }}{\% \text { EfficiencyNetwork } \times \text { Association Rate }} \\
N_{A P} & =\frac{0,786 \times 286 \times 0,75}{0,5 \times 144}=2,34=2
\end{aligned}
$$

Jadi jumlah AP yang dibutuhkan sebanyak 2 buah untuk setiap lantai. Setiap AP akan melayani sekitar 143 pengguna. Pemilihan spesifikasi AP juga berpengaruh pada jumlah pengguna yang dapat dilayani. Contoh perancangan peletakan AP untuk lantai 1 ditunjukkan pada Gambar 6.

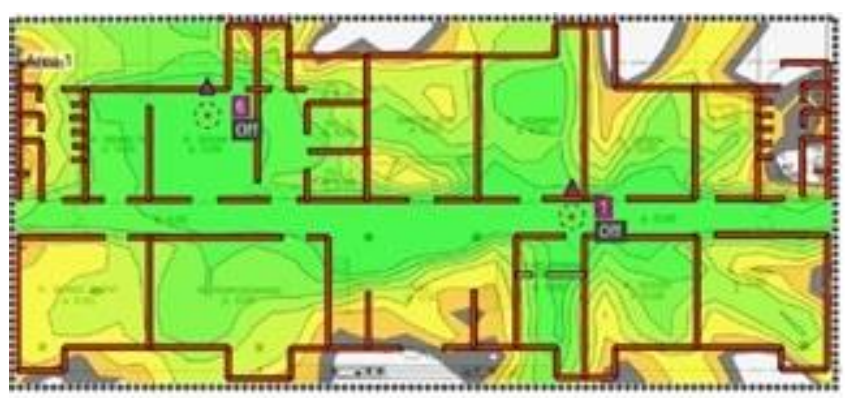

Gambar 6. Visualisasi perancangan peletakan AP di lantai 1

Hasil perancangan berdasarkan jumlah pengguna, kemudian dilakukan pengukuran signal strength dan SNR di setiap lantai, dan hasil presentase untuk setiap lantai ditunjukkan pada Tabel IV.

TABEL IV NILAI SigNAL STRENGTH DAN SNR BERDASARKAN JUMLAH PENGGUNA

\begin{tabular}{ccc|cc}
\hline \multirow{2}{*}{ Lantai } & \multicolumn{2}{c}{ Signal Strength } & \multicolumn{2}{c}{ SNR } \\
\cline { 2 - 5 } & $>-75 \mathrm{dBm}$ & $<-75 \mathrm{dBm}$ & $>25 \mathrm{~dB}$ & $<25 \mathrm{~dB}$ \\
\hline 1 & $86 \%$ & $13 \%$ & $81,1 \%$ & $17,9 \%$ \\
2 & $89,8 \%$ & $9,2 \%$ & $86,3 \%$ & $12,7 \%$ \\
3 & $92,9 \%$ & $6,1 \%$ & $90,8 \%$ & $8,2 \%$ \\
\hline \hline
\end{tabular}

\section{Analisa Optimasi}

Hasil sebelum dan setelah dilakukan optimasi terlihat pada Tabel V dan Tabel VI berikut ini:

\begin{tabular}{|c|c|c|c|c|c|c|}
\hline \multirow[b]{3}{*}{ Lantai } & \multirow{2}{*}{\multicolumn{2}{|c|}{ Sebelum }} & \multicolumn{4}{|c|}{ Sesudah } \\
\hline & & & \multicolumn{2}{|c|}{ Coverage Area } & \multicolumn{2}{|c|}{ Jumlah Pengguna } \\
\hline & $\begin{array}{c}\text { Jumlah } \\
\text { AP }\end{array}$ & $\begin{array}{c}>-75 \\
\mathrm{dBm} \\
(\%)\end{array}$ & $\begin{array}{c}\text { Jumlah } \\
\text { AP }\end{array}$ & $\begin{array}{c}>-75 \\
\mathrm{dBm} \\
(\%)\end{array}$ & $\begin{array}{c}\text { Jumlah } \\
\text { AP }\end{array}$ & $\begin{array}{l}>-75 \\
\mathrm{dBm} \\
(\%)\end{array}$ \\
\hline 1 & 6 & 93,7 & 2 & 86 & 2 & 86 \\
\hline 2 & 5 & 86,2 & 2 & 89,8 & 2 & 89,8 \\
\hline 3 & 2 & 93,6 & 1 & 81,9 & 2 & 92,9 \\
\hline \multicolumn{7}{|c|}{ TABEL VI PERBANDINGAN NILAI SNR } \\
\hline \multirow[b]{3}{*}{ Lantai } & \multirow{2}{*}{\multicolumn{2}{|c|}{ Sebelum }} & \multicolumn{4}{|c|}{ Sesudah } \\
\hline & & & \multicolumn{2}{|c|}{ Coverage Area } & \multicolumn{2}{|c|}{ Jumlah Pengguna } \\
\hline & $\begin{array}{c}\text { Jumlah } \\
\text { AP }\end{array}$ & $\begin{array}{c}>25 \\
\mathrm{~dB} \\
(\%)\end{array}$ & $\begin{array}{c}\text { Jumlah } \\
\text { AP }\end{array}$ & $\begin{array}{c}>25 \\
\mathrm{~dB} \\
(\%)\end{array}$ & $\begin{array}{l}\text { Jumlah } \\
\text { AP }\end{array}$ & $\begin{array}{l}>25 \\
\mathrm{~dB} \\
(\%)\end{array}$ \\
\hline 1 & 6 & 74,3 & 2 & 81,1 & 2 & 81,1 \\
\hline 2 & 5 & 59,8 & 2 & 86,3 & 2 & 86,3 \\
\hline 3 & 2 & 91,4 & 1 & 78,1 & 2 & 90,8 \\
\hline
\end{tabular}

TABEL V PERBANDINGAN NILAI SIGNAL STRENGTH
Pada Tabel V dan VI, terlihat hanya diperlukan paling banyak 2 AP untuk memenuhi kebutuhan seluruh area maupun pengguna dengan nilai signal strength dan SNR yang sesuai standar.

\section{KESIMPULAN}

Dari penelitian yang telah dilakukan, maka didapatkan kesimpulan sebagai berikut:

1. Pada kondisi sekarang dengan jumlah AP di lantai 1 6 buah, lantai 23 buah, dan 2 buah di lantai 3, didapatkan nilai presentase signal strength yang > $75 \mathrm{dBm}$ di lantai 1, 2, dan 3 adalah 93,7\%, 86,2\%, dan $93,6 \%$. Sedangkan nilai presentase SNR yang > $25 \mathrm{~dB}$ di lantai 1, 2, dan 3 adalah 74,3\%, 59,8\%, dan $91,4 \%$.

2. Hasil optimasi memperlihatkan hanya butuh 2 AP untuk setiap lantai untuk memenuhi kebutuhan layanan berdasarkan coverage area dan jumlah pengguna (sesuai dengan standar untuk signal strength dan SNR). Hal ini lebih bisa menghemat secara ekonomis dengan hasil yang sama yaitu terlayani untuk semua pengguna. Nilai persentase signal strength yang > $-75 \mathrm{dBm}$ setelah dilakukan optimasi adalah $86 \%, 89,8 \%$, dan $87,4 \%$ untuk lantai 1, 2, dan 3 secara berurutan. Sedangkan nilai persentase SNR yang > $25 \mathrm{~dB}$ setelah dilakukan optimasi adalah $81,1 \%, 86,3 \%$, dan $84,5 \%$ untuk lantai 1, 2, dan 3 secara berurutan.

\section{DAFTAR PUSTAKa}

[1]

"Wi-Fi (wireless networking)," www.webopedia.com, 2018. [Online]. Available: https://www.webopedia.com/TERM/W/Wi_Fi.html. [Accessed: 06-Jul-2018].

[2] T.-C. W. Shoa-Yei Yeong, Wafaa Al-Salihy, "Indoor WLAN Monitoring and Planning using Empirical and Theorical Propagation Models," IEEE, pp. 165$169,2010$.

[3] R. P. F. H. Cassio Bento Andrade, "IEEE 802.11 WLANS: A Comparison on Indoor Coverage Models," IEEE, 2010.

[4] H. N. Bekti Widyaningsih, Optimalisasi Area Cakupan Area Jaringan Nirkabel dalam Ruangan. Malang: Universitas Brawijaya, 2013.

[5] "Ekahau Site Survey," www.ekahau.com, 2018. [Online]. Available: https://www.ekahau.com/. [Accessed: 01-Sep-2018].

[6] R. N. Zawiyah Saharuna, "Desain Jaringan WLAN Berdasarkan Cakupan Area dan Kapasitas," Infotel, vol. 8, 2016.

[7] G. Victonida, Perancangan dan Simulasi Penempatan Access Point Wireless Berdasarkan Coverage Jaringan di Gedung Twin Tower Universitas Muhammadiyah Yogyakarta. Yogyakarta: Universitas Muhammadiyah Yogyakarta, 2017.

[8] U. K. U. Silmina Farhani Komalin, "Analisa 
Perancangan Indoor WiFi IEEE 802.11n pada Gedung Tokong Nanas (Telkom University Lecture Center)," Semin. Nas. Inov. dan Apl. Teknol. di Ind. 2016, pp. 356-361, 2016.

[9] T. Zani, "Perancangan High Density Wireless LAN 802.11n $2.4 \mathrm{GHz}$ di Ruang Kelas Fakultas Ilmu Terapan Universitas Telkom," Teknol. Inf, pp. 103107, 2017.

[10] M. U. Nuha, Analisa Probabilitas Co-Channel pada Jaringan Wireless Menggunakan Nodemcu Esp8266 untuk Sistem Cognitive Radio. Semarang: Universitas Islam Sultan Agung, 2017. 